\title{
FASTKD2-related infantile mitochondrial encephalomyopathy
}

INSERM

\section{Source}

INSERM. (1999). Orphanet: an online rare disease and orphan drug data base. FAST KD2related infantile mitochondrial encephalomyopathy. ORPHA:166105

FAST KD2-related infantile mitochondrial encephalomyopathy is a rare, genetic, mitochondrial oxidative phosphorylation disorder characterized by infantile-onset encephalomyopathy presenting with developmental delay, slowly progressive hemiplegia, intractable epileptic seizures and asymmetrical brain atrophy with dilatation of the ipsilateral ventricle system. Additional features include optic atrophy, mildly increased plasma and/or CSF lactate and decreased cytochrome c oxidase acitivity in skeletal muscle biopsy. 